\title{
26. WHOLE-CORE SPINNING AND DETECTION OF REVERSAL BOUNDARIES IN HYDRAULIC PISTON CORES FROM THE SOUTHWESTERN ATLANTIC: LEG $\mathbf{7 2}^{1}$
}

\author{
A. E. Suzyumov, P. P. Shirshov Institute of Oceanology of the U.S.S.R. Academy of Sciences, Moscow, U.S.S.R. \\ and \\ N. Hamilton, Department of Geology, University of Southampton, Southampton, United Kingdom
}

\begin{abstract}
A study has been made of downhole declination changes of the horizontal component of the natural remanent magnetization of unopened whole-core sections recovered by use of the hydraulic piston corer at DSDP Sites 515, 517, and 518. There is clear evidence that polarity reversal boundaries can be detected by this preliminary paleomagnetic technique. The Quaternary through late Neogene sediments studied reveal a record of the magnetostratigraphy over the past 4.5 Ma, although the quality of this record is better defined by the terrigenous sediments of the Brazil Basin than the biogenous oozes of the Rio Grande Rise.
\end{abstract}

\section{INTRODUCTION}

This contribution describes a paleomagnetic study of whole-core sections undertaken on board Glomar Challenger during Leg 72 . For shipboard studies, we used two Digico (UK) magnetometer systems: 1) a standard spinner magnetometer for measurements of natural remanent magnetization (NRM) of discrete samples, and 2) a long-core spinner magnetometer, which we used for determination of the relative downhole declination changes of the horizontal component of the NRM of the whole-core sections.

Although the technique of discrete sample remanence measurement of sediments has been used routinely on the Glomar Challenger since Leg 47A, satisfactory measurements by the long-core spinner magnetometer only became possible through the development of the hydraulic piston corer (HPC). This corer was first used routinely during Leg 68 . The HPC technique permits undisturbed and practically continuous recovery of soft sediments (the recovery normally exceeds $80 \%$ ). Providing that a sufficient sampling frequency is used in the long-core spinner measurements, the combination of the two techniques (HPC and whole-core spinning) has the potential of providing a much more complete record of geomagnetic field polarity changes in sedimentary sequences than conventional discrete sample studies alone. Each HPC core was oriented relative to the preceding one by the use of a simple device consisting of an aluminum ring and marker, which marks the position of pipe on the ring. Thus, ideally, the HPC provides an almost continuous and comparatively well-oriented lithologic column that ensures a greater degree of stratigraphic resolution and volume of information for all types of study, including paleomagnetic analysis.

During Leg 72, however, we faced some difficulties because the quality of HPC cores depended to a great

\footnotetext{
${ }^{1}$ Barker, P. F., Carlson, R. L., Johnson, D. A., et al., Init. Repts. DSDP, 72: Washington (U.S. Govt. Printing Office).
}

extent on the lithology. In the more cohesive sediments, consisting mainly of terrigenous material, the HPC recovered undisturbed sediment, except for the upper 5-10 $\mathrm{cm}$ or so of each 4.5-m core, which can be washed out or saturated with water. For example, at Hole 515A, the recovery was $89 \%$, and about $80 \%$ of sediments were undisturbed. In the soft biogenous sediments, however, disturbance was more common; the sediments became more or less saturated with water almost throughout the complete length of each core. At Site 517, for example, the recovery was $95 \%$ but only $46 \%$ of the recovered interval was undisturbed. Obviously the coring disturbance hinders paleomagnetic measurements, and the whole-core spinner magnetometer is particularly sensitive to it.

The whole-core spinner magnetometer provides a means of measuring the relative declination of the horizontal component of the remanence. Polarity reversal boundaries should be represented in the results as approximately $180^{\circ}$ declination changes. But the sign of each magnetic polarity interval can be determined only by reference to the remanent inclination of the discrete samples. The whole-core spinner magnetometer provides an opportunity to carry out the measurements with high frequency at intervals of a few centimeters along each section. Such a high frequency of sampling of discrete samples is almost impossible on a large scale as part of normal shipboard procedures.

Thus the combination of these two methods raises the reliability of the paleomagnetic method as a whole and aids the determination of magnetostratigraphy. During Leg 72 , we used this combination in all cases when possible, namely at Hole 515A and Sites 517 and 518. Hole 515A lies in the southern Brazil Basin; Sites 517 and 518 lie on the flank of the Rio Grande Rise.

\section{METHODS}

Measurements by whole-core spinner magnetometer were made for a large number of whole-core sections (Table 1). For example, at Hole 515A, 65 whole-core sections were measured (the length of each section measured was $1.5 \mathrm{~m}$ or less, but not less than $0.5 \mathrm{~m}$ ) from 27 
HPC cores. These investigations were supplemented by remanence measurements on the standard spinner magnetometer of discrete samples taken at an approximate frequency of $0.5 \mathrm{~m}$ downhole after splitting the same core sections (for Hole 515A, 183 discrete samples were measured). We did not use any preliminary magnetic cleaning for NRM measurements on the whole-core spinner magnetometer. Normally the measurements were made at an interval of $10 \mathrm{~cm}$ down-section, but for some sections measurements were made every $5 \mathrm{~cm}$ or every $2 \mathrm{~cm}$. Several individual sections were subjected to repeat measurements, and some horizons were measured three or more times. In this way, we were able to determine: 1 ) whether reversal events or excursions of the geomagnetic field are likely to be missed with the $10-\mathrm{cm}$ interval of measurements, and 2) the repeatibility of individual measurements.

\section{ACCURACY OF MEASUREMENTS}

Values of declination usually repeated within $\pm 5^{\circ}$, and $40 \%$ of repeats only differed from each other by an angle of $\pm 2.5^{\circ}$ (Fig. 1A). Some measurements showed large differences up to $100^{\circ}$, but these variations were of random character, and, as can be seen in Figure 1A, there were not statistically significant.

One example of both $10-\mathrm{cm}$ and $5-\mathrm{cm}$ steps for measurement on the same core section is shown in Figure 1B. The curve for the shorter sampling interval is somewhat more complicated, but there are no major changes in it that are not reflected in the curve for the wider sampling interval. Therefore, in general, the long-core spinner magnetometer seems to provide sufficiently reliable data from the $10-\mathrm{cm}$ interval of measurements, and the error of the declination values thus obtained is generally no worse than $10^{\circ}$. At a reversal boundary, the declination of magnetic vector changes by approximately $180^{\circ}$, so this accuracy is quite acceptable. Furthermore, the resolution of the polarity record depends also on the sedimentation rate; fortuitously at the Leg 72 sites, the rates are moderately fast, for example, about $20 \mathrm{~m} /$ Ma for Hole 515A.

\section{HOLE 515A}

\section{Lithology}

Hole 515A penetrated, with the use of the HPC, nearly two-thirds of Lithologic Unit 1 of the sedimentary sequence encountered at Site 515 in the Brazil Basin. This unit, of Quaternary through Pliocene age, consists of grayish brown terrigenous mud with occasional nannofossil-rich layers and some foraminifer-rich layers. The

Table 1. Sites where measurements were made by whole-core spinner magnetometer.

\begin{tabular}{lccc}
\hline Characteristic & Hole 515A & Hole 517 & Hole 518 \\
\hline Latitude & $26^{\circ} 14.31^{\prime} \mathrm{S}$ & $30^{\circ} 56.81^{\prime} \mathrm{S}$ & $29^{\circ} 58.42^{\prime} \mathrm{S}$ \\
Longitude & $36^{\circ} 30.17^{\prime} \mathrm{W}$ & $38^{\circ} 02.47^{\prime} \mathrm{W}$ & $38^{\circ} 08.12^{\prime} \mathrm{W}$ \\
Water depth, m & 4252 & 2963 & 3914 \\
Penetration, m & 107.9 & 50.9 & 76.7 \\
\% recovery & 89 & 95 & 78 \\
\% undisturbed & 80 & 46 & 56 \\
$\begin{array}{l}\text { sediments } \\
\text { Lithology }\end{array}$ & $\begin{array}{c}\text { Terrigenous } \\
\text { mud }\end{array}$ & $\begin{array}{c}\text { Foraminiferal- } \\
\text { nannofossil }\end{array}$ & $\begin{array}{c}\text { Foraminiferal- } \\
\text { nannofossil } \\
\end{array}$ \\
& & ooze & ooze \\
\hline
\end{tabular}
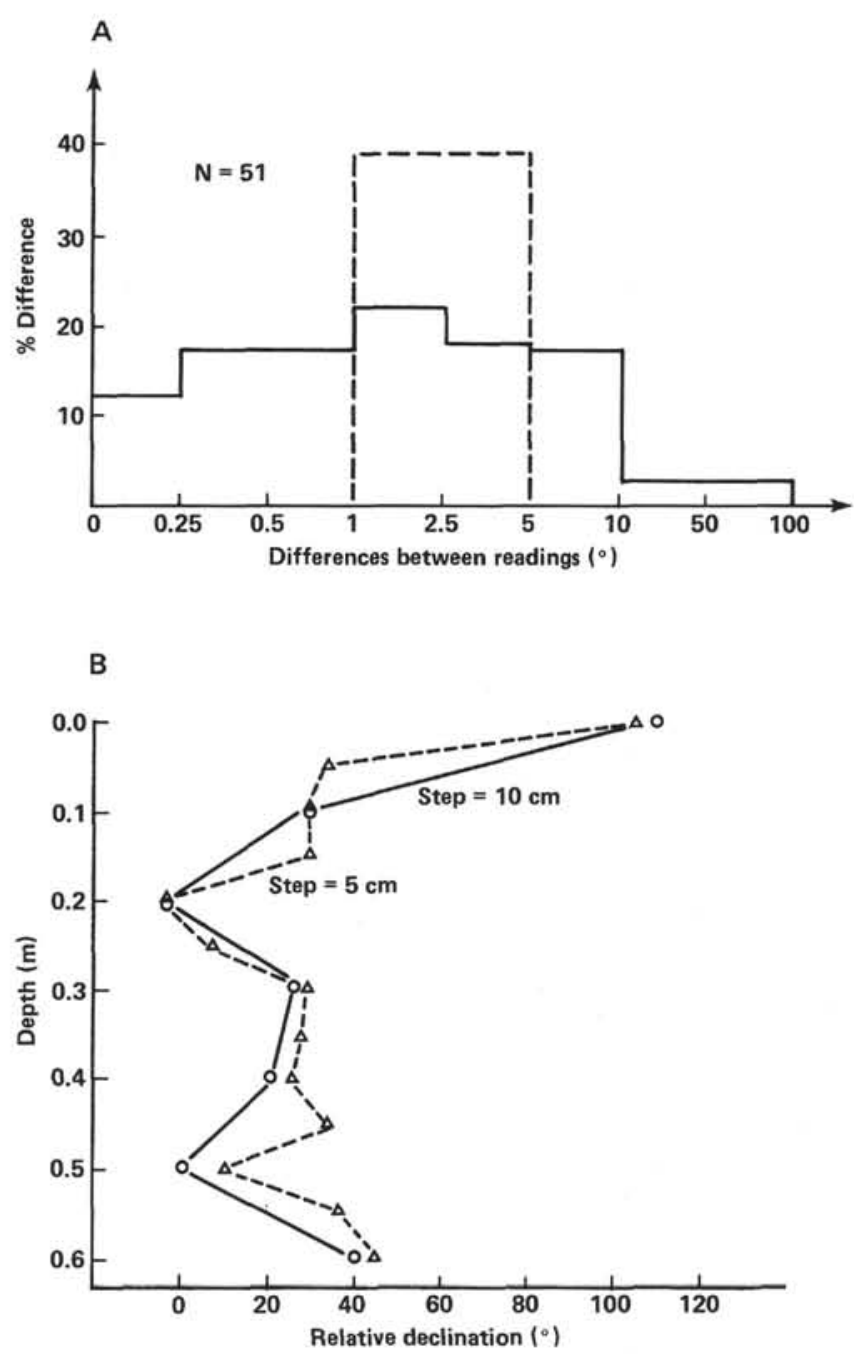

Figure 1. Accuracy of measurements by the whole-core spinner magnetometer. A) Distribution of differences between repeated declination readings at several levels. $\mathrm{N}=$ number of samples. Dashed line shows $40 \%$ of repeated declinations lie within $1-5^{\circ}$ of each other. B) Two curves showing readings from the whole-core spinner magnetometer for the same section with 10 and $5 \mathrm{~cm}$ measuring points.

paucity of laminations throughout that section suggests that there was not much variation in the near-bottom flow regime during deposition of this unit and consequently indicates that there are no major hiatuses present. Practically all cores recovered with the use of the HPC were in good condition, particularly in comparison with the cores obtained by conventional rotary drilling of Holes 515 and 515B.

\section{Results of Measurements}

Whole-core sections from the upper $17.5 \mathrm{~m}$ of the Hole 515A (Cores 1 to 4 ) reveal extremely consistent values of declination except for several insignificant deviations and some scattering of values in the upper part of each core. This homogeneous interval corresponds to deposition during the Brunhes Epoch. The Brunhes/ Matuyama boundary occurs between Cores $515 \mathrm{~A}-4$ and $515 \mathrm{~A}-5$. The relative orientation device helps to fix the 
change of declination values at approximately $180^{\circ}$, but the nature of the polarity transition itself could not be traced there.

Unlike the Brunhes Epoch, a larger scatter of measured declination values down to $29 \mathrm{~m}$ depth sub-bottom characterizes the Matuyama Epoch at Hole 515A. Nevertheless, at $24.5-25.8 \mathrm{~m}$ depth, two polarity changes could be seen. The interval between them probably corresponds to the Jaramillo Event. A clearly defined normal polarity interval occurs between 33.0 and $34.2 \mathrm{~m}$ sub-bottom (Fig. 2). A reversal at $39.4-41.8 \mathrm{~m}$ sub-bottom corresponds to the Olduvai Event. Below this depth, between 43.3 and $44.0 \mathrm{~m}$, and again at $49.0 \mathrm{~m}$, marked declination changes occur (Fig. 2), which may represent possible geomagnetic excursions.

A $180^{\circ}$ change of declination values at $51.5 \mathrm{~m}$ subbottom (base of Core 515A-12) distinctly marks the boundary between the Matuyama and Gauss epochs. According to the whole-core spinning, the Gauss Epoch is complicated. One of the short reversed events of this epoch seen at 69.4-70.5 m sub-bottom possibly correlates to the Mammoth Event. At $77 \mathrm{~m}$ depth, a further reversal boundary, perhaps the Gauss/Gilbert boundary, was determined, but it is not so distinct as those mentioned above. Within the Gilbert Epoch, we can determine the event "a" (88-93 m sub-bottom) and complex double event "b" (95.3-97.8 m sub-bottom).

The majority of the geomagnetic field reversals known from standard paleomagnetic polarity time scales back to $4.5 \mathrm{Ma}$ are reflected in the whole-core spinning data obtained at Site 515. The absence of a few individual polarity boundaries can be explained by voids in the cores, or by drilling disturbance, or finally by difficulties in interpretation of data. The latter mainly concerns shorter polarity events.

\section{Comparison of Data and Magnetostratigraphy}

A comparison of the long-core spinning results and discrete samples results indicates that, at Hole 515A, the whole-core spinning data and NRM measurements of discrete samples are very similar (Fig. 2). Shore-based alternating field (AF) demagnetization confirms that Lithologic Unit 1 possesses a generally stable remanence (see site chapter, Site 515, this volume). Some of the well-determined boundaries include:

1) $32-36 \mathrm{~m}$ depth (Core 515A-8). Within the Matuyama Epoch, both paleomagnetic methods reveal evidence of reversals of the geomagnetic field. The discrete sample data show some complexity (Fig. 3A). At 34.2$35.2 \mathrm{~m}$ sub-bottom, NRM inclination and declination show a possible excursion of the geomagnetic field, before a normal polarity event (32.8-34.2 m sub-bottom). After AF demagnetization, the apparent length of the normal polarity event is shortened (Fig. 3a).

2) $41-45 \mathrm{~m}$ sub-bottom (Cores $515 \mathrm{~A}-10$ and $515 \mathrm{~A}$ 11). At $39.5 \mathrm{~m}$ and $41.8 \mathrm{~m}$, both methods delineate the reversal boundaries representing the upper and the lower limits of the Olduvai Event respectively (see Fig. 2). At $43 \mathrm{~m}$, declination changes in the whole-core spinning data may reflect a possible excursion of the geomagnetic field (Fig. 3B). After the AF demagnetization, these data do not radically change.
3) 50-53 m sub-bottom (Core 515A-12). The Matuyama/Gauss boundary occurs at $51.5 \mathrm{~m}$. Figure 3C shows the excellent correspondence between the wholecore spinning data and the NRM and demagnetized directions of discrete samples within this depth interval.

These three examples demonstrate the close agreement between the results of discrete sample remanence measurement and long-core spinning data. Polarity changes are well determined by both inclination and declination data; and further examples of this correspondence are easily recognized in Hole 515A paleomagnetic data.

\section{SITE 517}

\section{Lithology}

Only one lithologic unit was recovered at Site 517. It consists of Quaternary through Pliocene yellowish brown foraminiferal-nannofossil ooze with no visible evidence of bottom current activity. Although the recovery from use of the HPC is very high, coring disturbance is much worse than at Hole 515A (Table 1). Only 40 discrete samples were obtained at this site, characterizing $42 \%$ of the length drilled. We rotated 31 whole-core sections using the long-core spinner magnetometer unit, and this enabled us to characterize $46 \%$ of the hole length. Because several intervals in both methods do not overlap each other, the two paleomagnetic methods cover a total of $62 \%$ of the hole length.

\section{Results of Measurements}

In spite of the fact that we spun core sections practically from the entire range of the HPC recovery at Hole 517 , we obtained meaningful results only for samples from depths exceeding $14.5 \mathrm{~m}$ sub-bottom. According to discrete sample study and to biostratigraphy (site chapter, Site 517, this volume), this part of the section most probably corresponds to the late Matuyama Epoch. We identify the base of the Jaramillo event at a depth of $15.2 \mathrm{~m}$ (Fig. 4). The interval below this depth is of reversed polarity down to $18.5 \mathrm{~m}$ (Fig. 5). At $20-21 \mathrm{~m}$ subbottom, an interval of uniform polarity is recorded, but as the individual samples from this interval were not obtained, it is impossible to determine its sign.

At $31.1 \mathrm{~m}$ depth, the change of declination phase marking the Gauss/Matuyama boundary is recorded (Fig. 4). The Gauss Epoch at this site is somewhat better defined by our whole-core spinning measurements than are the younger epochs. A uniform interval of normal polarity is recorded below $31.1 \mathrm{~m}$, but at $39.3 \mathrm{~m}$ and $40.8 \mathrm{~m}$ two polarity changes occur. The event between them probably corresponds to the Kaena Event. At 41.2 $\mathrm{m}$, one more polarity change occurs; below it, the Mammoth Event is seen down to $42 \mathrm{~m}$.

Despite difficulties in interpreting data from the lower part of Hole 517, an indication of another polarity change at a depth of $45.5 \mathrm{~m}$ probably corresponds to the Gauss/Gilbert boundary (Fig. 5). Below this depth, the whole-core declination data shows more uniform behavior. This uniformity suggests that down to the lowest depth of the hole $(50.9 \mathrm{~m})$, no further reversals are present. 

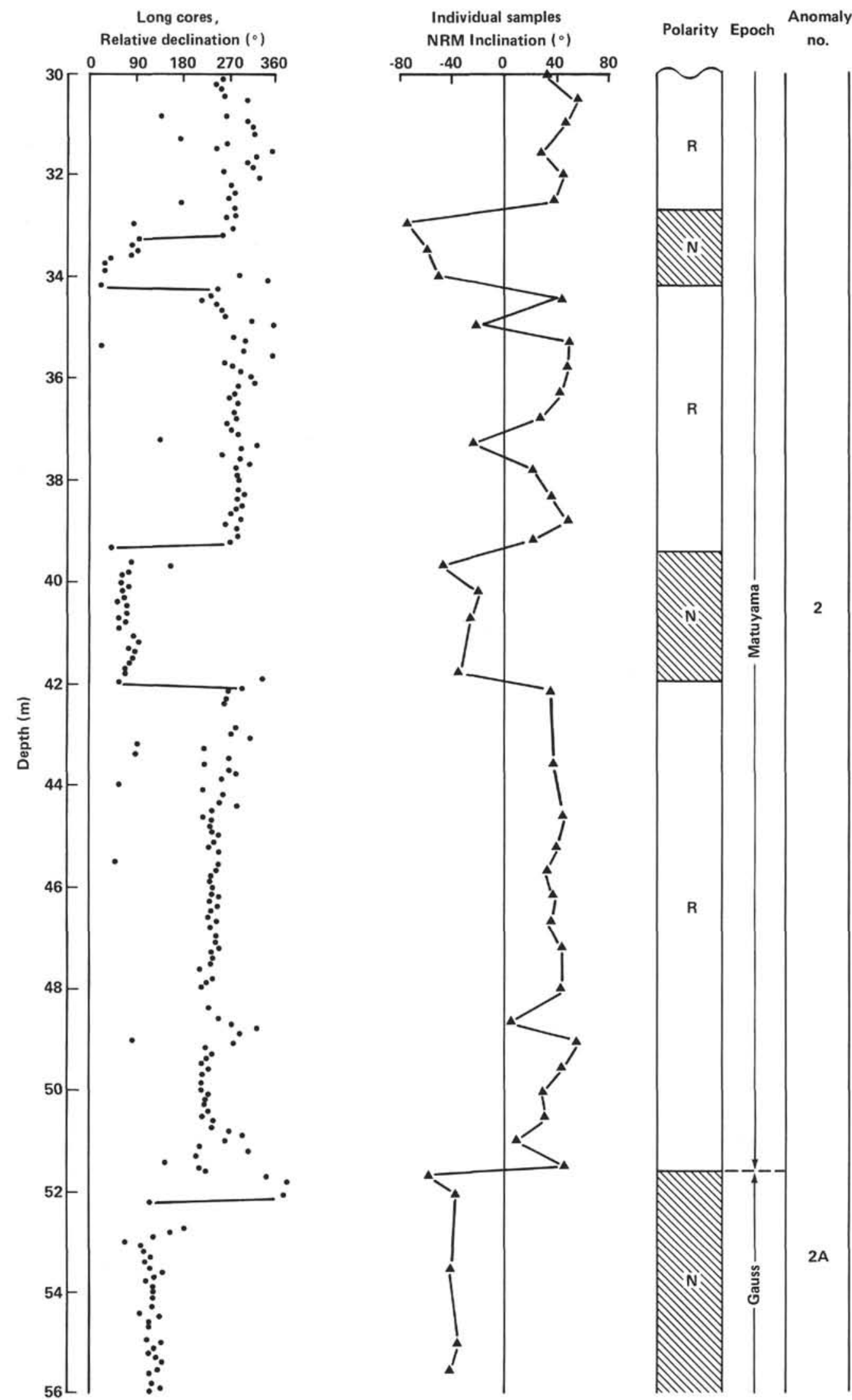

Figure 2. Hole 515A: an example of data correspondence (long-core spinning data and individual samples) and the magnetostratigraphy. $\mathrm{NRM}=$ natural remanent magnetization; $\mathrm{N}=$ normal; $\mathrm{R}=$ reversed. 
Comparison of inferred magnetic polarity stratigraphy obtained from discrete samples (Column 1) and the whole-core spinning (Column 2) shows their complete correspondence (Fig. 5). This match is particularly well expressed for the Gauss Epoch in which two short reversed events (the Kaena and the Mammoth) are recorded in both Columns 1 and 2 in the interval between 39.4 and $42 \mathrm{~m}$ sub-bottom (also see Fig. 4).

\section{SITE 518}

\section{Lithology}

Two lithologic units ranging in age from early Miocene through Pleistocene, were recorded at Site 518: calcareous oozes (0-54 m) and terrigenous muds and marly nannofossil oozes (54.7-57.4 m). Seventy-seven discrete samples were obtained from this hole, and 18 sections were rotated on the long-core spinner magnetometer. Preliminary examination showed that the other sections had voids, "soupy" disturbances, and excessive water between liner and sediment surface, irregularities that would hinder our measurements.

\section{Results of Measurements}

Despite a careful preliminary selection of suitable sections, the results as a whole are no better in quality than those at Site 517. Polarity changes are recorded at $12.1,13.6,15.3$, and perhaps at $18.1 \mathrm{~m}$. The latter zone probably is related to the Olduvai Event. A polarity change at $22 \mathrm{~m}$ corresponds to the Matuyama/Gauss boundary. From $29.4 \mathrm{~m}$ to $34.6 \mathrm{~m}$ sub-bottom, wholecore spinning reveals two intervals of constant polarity separated by an unmeasured $1.5 \mathrm{-m}$ core section. Subsequent discrete sample study of that section shows that its normal polarity is the same as the sediment above and below; therefore, we assign the interval from 29.4 to $34.6 \mathrm{~m}$ to the lower Gauss Epoch.

\section{THE CHARACTERISTICS OF THE PROCESS OF POLARITY CHANGES (according to the whole-core spinning data)}

The whole-core spinning data provide an opportunity to examine the character of polarity transitions. The process of the polarity change is characterized by three main parameters: duration, changes of geomagnetic field intensity, and changes of angular values of inclination and declination. We can analyze the reversal process by a consideration of these parameters.

1) The duration of the reversal process was determined for 13 boundaries of polarity change and for possible short excursions of the geomagnetic field at Holes $515 \mathrm{~A}$ and 517. The assumed sedimentation rate is one of the most critical parameters in any computation of the time duration of the process of polarity change. Estimates of sedimentation rate depend in turn on the reliability of the available age controls, both biostratigraphic and magnetostratigraphic. Hole 515A lacks good biostratigraphic control, restricting us to its magnetostratigraphy. In contrast, excellent biostratigraphic ages are available for Hole 517. The average duration of a polarity transition as indicated by change in declination val- ues at the most distinctly determined boundaries, is approximately 10,000 to 12,000 years (Table 2 ). The socalled excursions of the geomagnetic field appear to have the same duration. These values are close to those described by Creer and Ispir (1970) or approximately double the most precise definitions (Opdyke et al., 1973, Dunn et al., 1971). Our data probably do not possess the necessary precision for better determination of the rate of the geomagnetic polarity change, or the duration of this process, because the duration of the declination change is often somewhat longer than that of the inclination. If one measures the duration of the polarity change by the time when intensity of the geomagnetic field is considerably decreased, the duration of this process is somewhat longer than when they are determined by the declination changes, as noted earlier by Dunn and others (1971) and Hillhouse and Cox (1976) among others.

2) Under favorable circumstances, an indication of variation in strength of the geomagnetic field during a polarity transition may be obtained by monitoring the magnitude of the sediment remanent intensity (e.g., Ninkovich et al., 1966). This approach is limited because it excludes other independent sedimentologic or diagenetic causes for fluctuations in remanent intensity. Nevertheless, because whole-core spinning allows simultaneous determination of the magnitude of the horizontal component of the remanence and declination, we have data that overcome this limitation for the polarity boundaries that we have identified. The most distinct data are obtained for Hole 515A (Fig. 3), mainly a result of the fidelity afforded by higher magnetization of terrigenous sediments of the Brazil Basin compared with the carbonate-rich layers of the Rio Grande Rise (Sites

Table 2. Duration of the polarity change process according to the whole-core-spinning data as recorded in Leg 72 sediments.

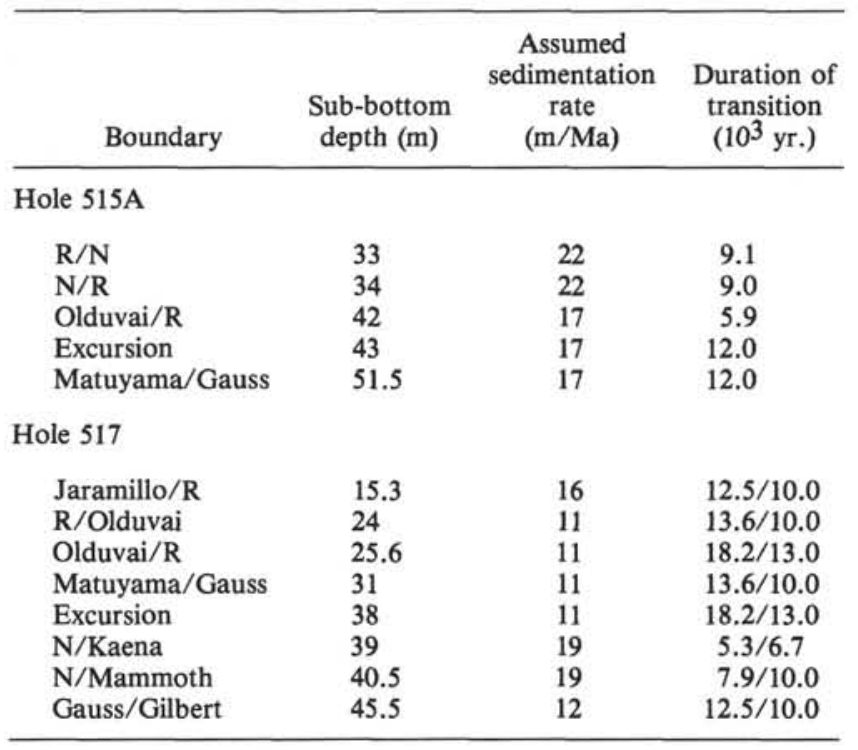

Note: $\mathrm{N}=$ normal polarity, $\mathrm{R}=$ reversed polarity. Two results of calculations for duration of the reversal process are given for Site 517: (to the left of the slash) according to the assumed sedimentation rate, and (to the right of the slash) according to an average sedimentation rate of $15 \mathrm{~m} / \mathrm{Ma}$. 
A

Declination $\left({ }^{\circ}\right)$

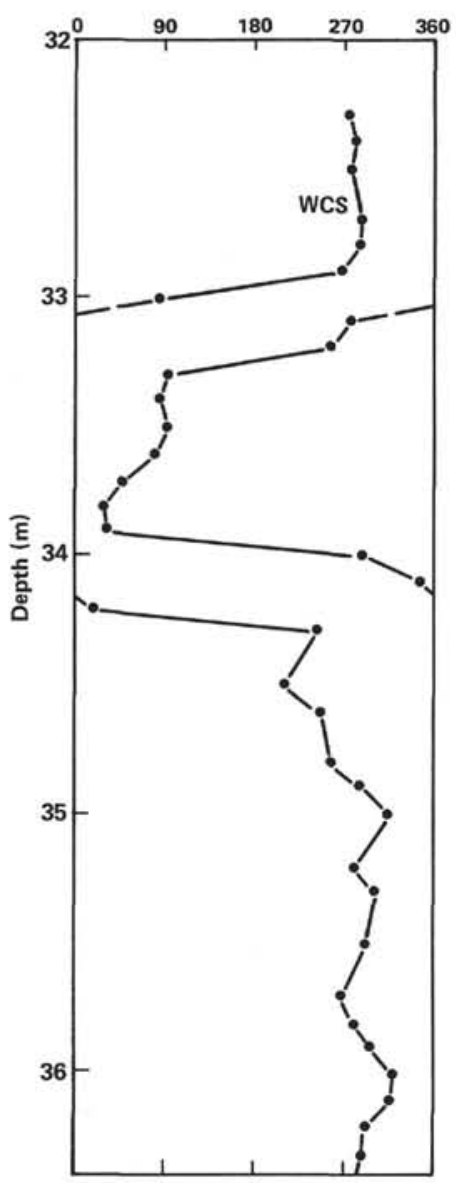

Declination $\left({ }^{\circ}\right)$

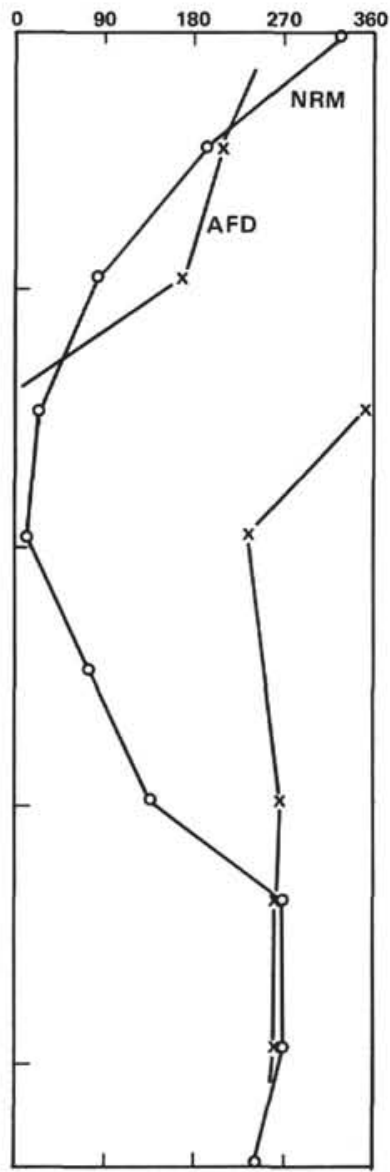

Inclination $\left({ }^{\circ}\right)$

Horizontal component

intensity

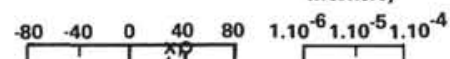

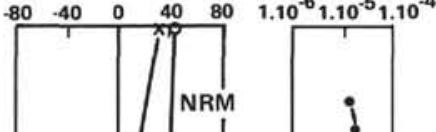

Figure 3. Detailed comparison of data obtained by the whole-core spinner magnetometer and by measurements of discrete samples, Hole 515A. WCS = whole-core spinner data; NRM = natural remanence magnetization data from measurements of discrete samples; AFD: discrete sample measurements after cleaning in alternating field. Data for 32-36 m depth (A), 41-45 m depth (B), and 50-53 m depth (C). 
WHOLE-CORE SPINNING AND REVERSAL BOUNDARIES

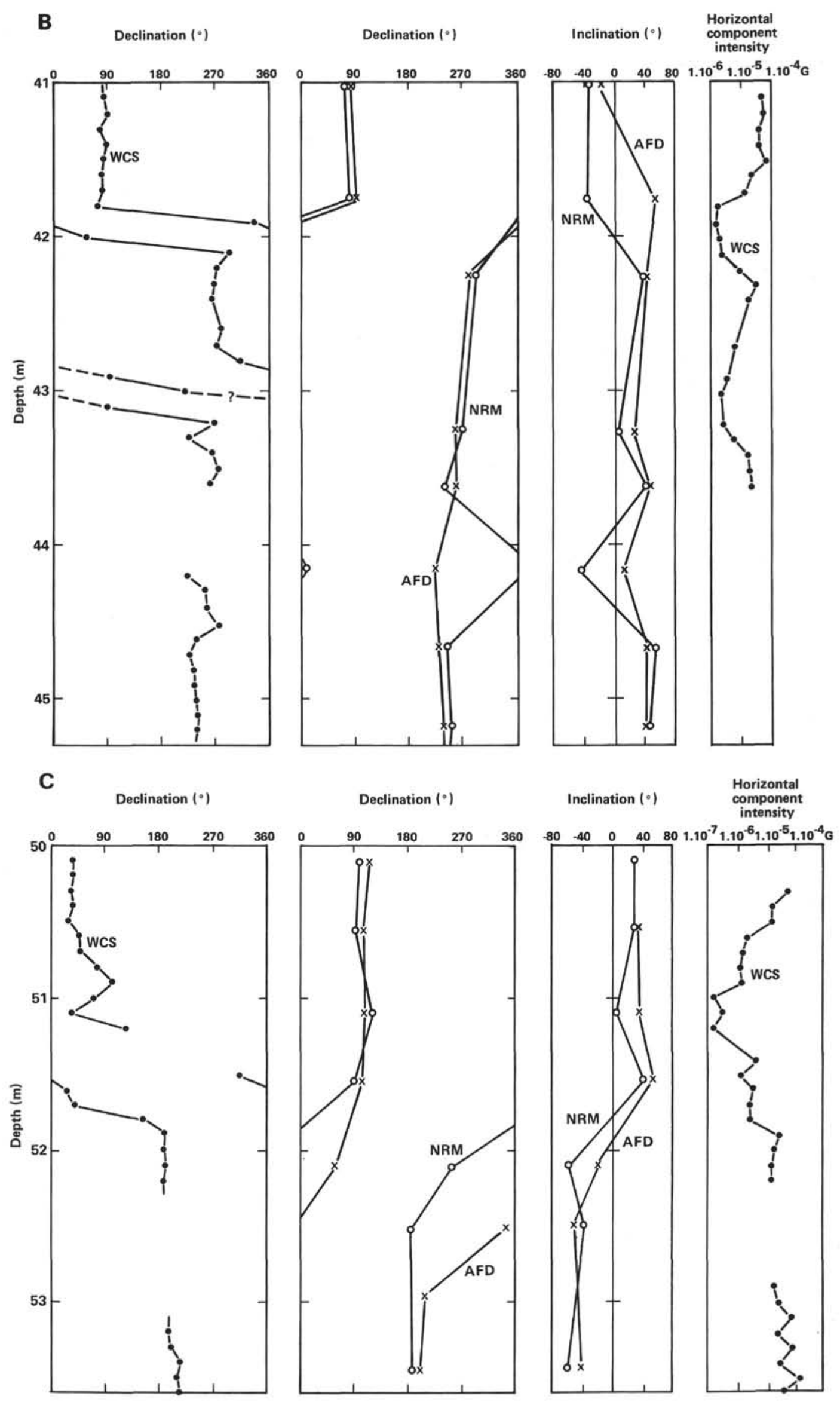

Figure 3. (Continued). 

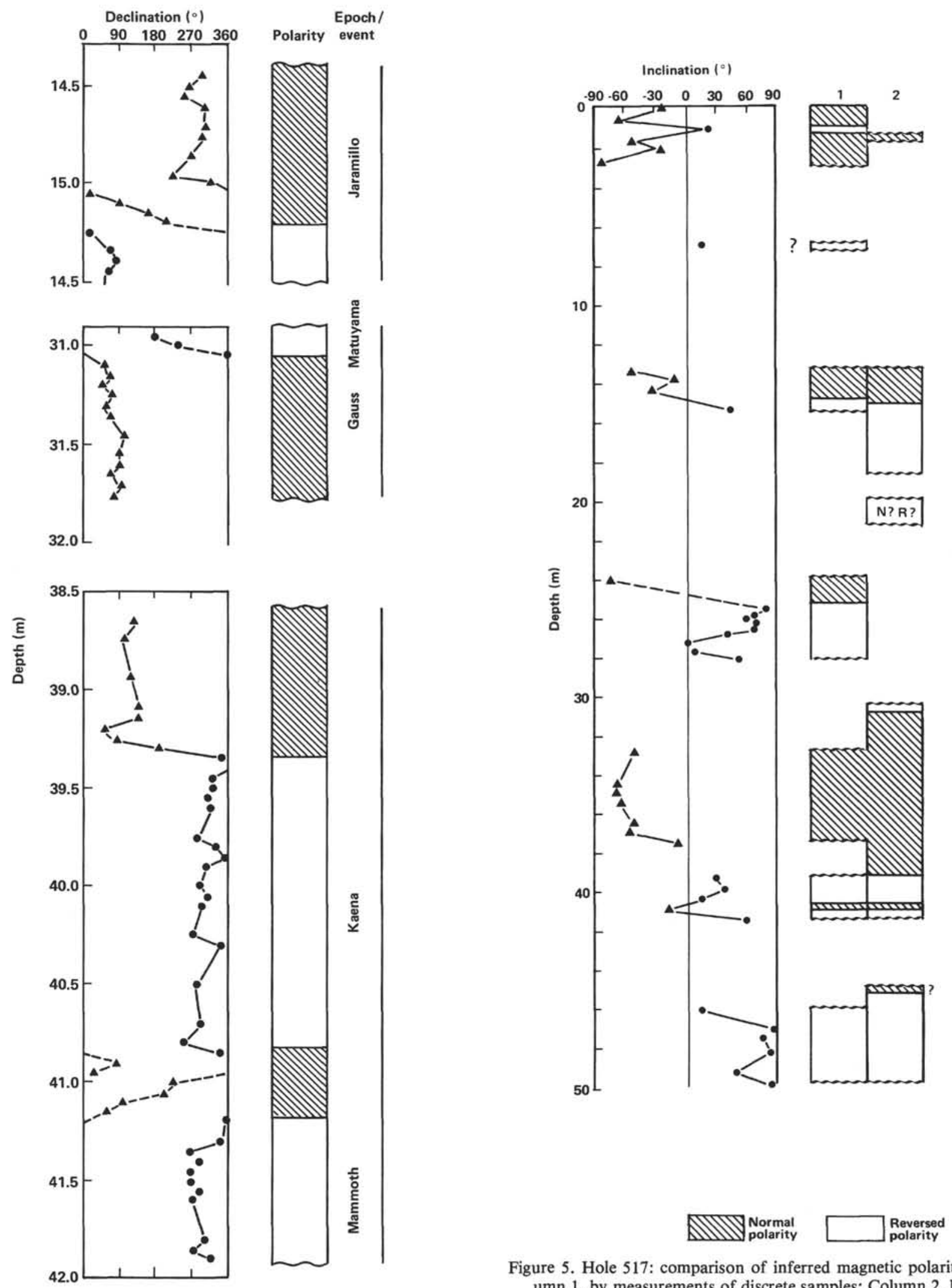

Figure 5. Hole 517: comparison of inferred magnetic polarity: Column 1, by measurements of discrete samples; Column 2, by measurements made by the whole-core spinner magnetometer.

Figure 4. Hole 517: change of declination values at the boundaries of episodes of opposite polarities by measurements made by the whole-core spinner magnetometer. 
517 and 518). At Hole 515A, the horizontal component of remanent intensity is normally between $10^{-2}-10^{-1}$ $\mathrm{A} / \mathrm{m}$ during the stable periods of constant polarity; during the reversal of the geomagnetic field, it is reduced to one-tenth or even one-hundredth of the original level. These observations correspond with data from other studies (Gurary, 1968). Results obtained are generally similar for Holes 517 and 518, but the scatter of remanent intensity values is much greater than for Hole $515 \mathrm{~A}$, especially during reversals.

3) The change of angular values of geomagnetic field (declination in our study) during the reversals is of greatest interest. Figures 2 and 3 show clearly the correspondence between the character of declination and the inclination changes. This correspondence allows the determination of geomagnetic field reversal boundaries from the whole-core spinning data, and we can use this data to examine in detail the process of polarity change.

As shown by measurements of discrete samples, polarity reversals are reflected simply by a change of the inclination's sign and an approximately $180^{\circ}$ declination change. According to the whole-core spinning data, a reversal develops in a more complex manner. At Site 517 for instance, measuring at a $5-\mathrm{cm}$ interval, the transition to the Jaramillo Event shows that declination values change not just by $180^{\circ}$, but by $360^{\circ}+180^{\circ}$ (Fig. 4). Examples of the same phenomenon also occur at Hole 515A (Fig. 3A-B). According to the same data, excursions of the geomagnetic field appear to be reflected by the declination changes of two full periods $\left(360^{\circ}+\right.$ $360^{\circ}$, Fig. 3B). An alternative explanation requires that between two stable positions of the geomagnetic pole the whole-core spinning data demonstrate its chaotic movement. We think that the regular character of smooth continuous declination change during the reversal process corresponds better to the existing models of the geomagnetic dynamo behavior.

The problem of estimation of the virtual geomagnetic pole's (VGP) trajectory has been considered by a number of authors. The existing earlier concept that during this process the pole moves in the limits of certain section of the globe (Steinhauser and Vincenz, 1973) has not been confirmed by calculation of the VGP trajectories for results from different parts of the world (Opdyke et al., 1973; Gurary, 1973). Thus, Opdyke and others (1973) ascertained that the trajectories of virtual poles for a set of consecutive events, Olduvai/Matuyama/ Jaramillo/Matuyama determined for an Indian Ocean core, differ considerably from each other and from the preferred trajectory suggested by Creer and Ispir (1970).

Gurary (1973), who investigated the reversal process at the Gauss/Matuyama boundary in Middle Asia, reached the same conclusion. He also drew attention to the fact that, depending on the frequency of sampling, one can obtain quite different trajectories of VGP movement for the same reversal boundary. On the basis of these conclusions plus statistical processing of data for several well-determined boundaries, Vadkovsky and others (1980) reasoned that, during the polarity change process, certain trajectories of VGP's are not possible.
For the Matuyama/Jaramillo boundary studied in two outcrops of West Turkmenia (one of which represents a marine sequence and the other a continental one), Gurary (1981) provided the following description of its main features: 1) considerable decrease of intensity of the geomagnetic field (tenfold or even more) occurs; 2 ) every reversal starts with a decrease of intensity (against this background the polarity change occurs) and finishes with the restoration of the previous intensity level of the geomagnetic field; 3 ) the movement of the VGP mainly occurs in the western hemisphere (for certain set of measurements) in the Atlantic Ocean and Americas; and 4) the movement of poles is of irregular character: against a background of their displacement in a north-south direction, loops, returns and grouping of calculated pole's positions exist. The duration of polarity change process is estimated to be between 10,000 to 15,000 years.

Due to high sedimentation rates in Middle Asia sequences (about $200 \mathrm{~m} / \mathrm{Ma}$ ), the reversal process can be investigated in detail. For the marine sediments, the transitional zone is up to $20 \mathrm{~m}$ thick. In the continental sediments, it is lower (about $3 \mathrm{~m}$ ). The intensity of remanent magnetization is an order of magnitude lower in the Middle Asia sequences than in the Leg 72 sediments. The further decrease of intensity during the reversal process (by a factor of 10 to 100) makes these values commensurate with the lower level of the magnetometer's sensitivity.

A combination of lower magnetization during the reversal transition and rapid changes in the orientation of the remanent vector create some measurement and interpretation problems. For instance, it is impossible to use conventional statistical methods for the calculation of average VGP positions over a larger stratigraphic interval. The VGP method is usually most reliable for uniform polarity zones.

On the basis of the whole-core spinning, calculation of the position of paleopoles is impossible because neither the direction of remanent magnetization nor the absolute azimuthal orientation is known. However, in this study, unlike in the West Turkmenia study described above, the increase of frequency of measurements does not affect the regular character of declination changes. The declination change appears to consist of two parts: at first declination values change by a full period, then by half a period. As a result, the geomagnetic pole moves to the new position opposite to the previous one. The regular character of declination changes schematized in Figure 6 agrees with some models of geomagnetic dynamo, specifically the so-called "easy dynamo" of Brodsky (1981).

\section{CONCLUSIONS}

The joint paleomagnetic study during Leg 72 of discrete samples and long cores has confirmed that the polarity reversal boundaries can be detected before splitting cores open. The results, are, however, better defined for the highly magnetized terrigenous sediments of the Brazil Basin than for the weakly magnetized bioge- 

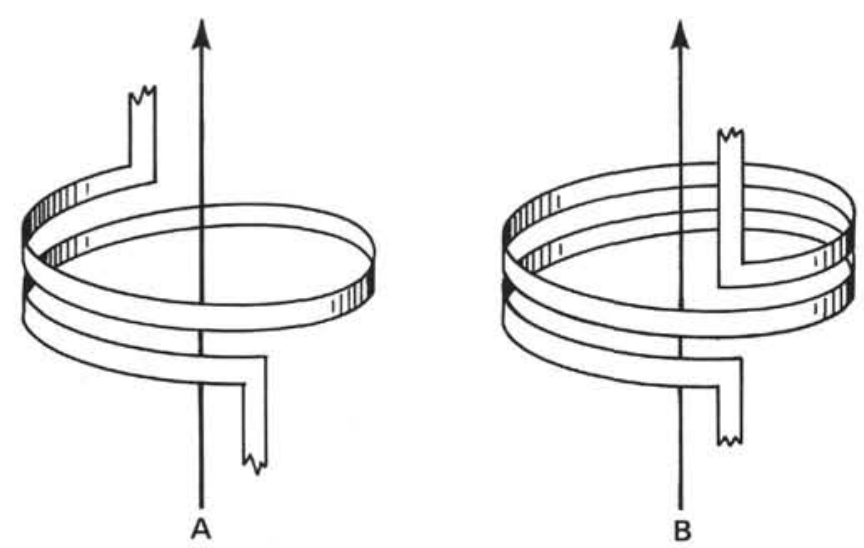

Figure 6. The geomagnetic field polarity transition as reflected in declination change. A, probable character of geomagnetic reversal; B, excursion of the field.

nous oozes of the Rio Grande Rise. Apparently both the intensity of magnetization of the sediments and their cohesiveness determine the reliability of the whole-core data.

In summary, the whole-core spinning registers declinations within the range of deviation not worse than $10^{\circ}$. Polarity reversal boundaries should be represented in these measurements as approximately $180^{\circ}$ declination change. The long-core spinning technique allows detailed measurements of individual core sections, in some cases at $2-\mathrm{cm}$ or 1,300-yr. intervals, assuming a sedimentation rate of $15 \mathrm{~m} / \mathrm{Ma}$. Even at the standard $10-\mathrm{cm}$ interval and the same sedimentation rate, the sampling frequency would represent $6,500 \mathrm{yr}$. On the basis of a time estimate of between 5,000 and 15,000 yr. for a geomagnetic polarity reversal, individual readings should not miss separate reversals and should provide a reliable means for detecting the process of transition. The whole-core spinning data reflect the majority of the geomagnetic field reversals during the past $4.5 \mathrm{Ma}$. $\mathrm{Ab}-$ sence of some individual polarity boundaries can be explained by voids in the cores, or by drilling disturbance, or by difficulties in interpretation of data during shortterm changes of polarity and possible geomagnetic field excursions.

Reversals occur against a background of reduced intensity of geomagnetic field. The reduction of intensity usually starts a little earlier than the polarity change itself, and both changes finish practically simultaneously. As far as the change of angular values of the geomagnetic field is concerned, we think that our data reveal a regular movement of the geomagnetic pole. At first declination values change by a full period and then by half a period; after that the episode of new polarity begins. It appears that geomagnetic field excursions are reflected by a geomagnetic pole displacement of one or two full periods.

\section{ACKNOWLEDGMENTS}

We are grateful to Dr. E. Mirlin and Dr. E. A. Hailwood for reviewing the manuscript and for suggesting modifications and improvements.

\section{REFERENCES}

Brodsky, Y.A., 1981. On a possible mechanism of geomagnetic dynamo, Geom. Aeron., (4):720-726; 21(5):890-897.

Creer, K. M., and Ispir, Y., 1970. An interpretation of the behavior of the geomagnetic field during polarity transition. Phys. Earth Planet. Inter., 2:283.

Dunn, J. R., Fuller, M., Ito, H., and Schmidt, V. A., 1971. Paleomagnetic study of a reversal of the earth's magnetic field. Science, 172:840-845.

Gurary, G. Z., 1968. On the character of the geomagnetic field during reversals. Trans. Acad. Sci. USSR, 178(5):1065-1068. 1973. Investigation of the geomagnetic field reversal at a Gauss/Matuyama boundary. Paleomagnetic Analysis in the Quaternary Deposits and Volcanic Rock Studies: Moscow (P. H. "Nauka").

1981. The Matuyama/Jaramillo geomagnetic reversal boundary studied on the territory of the Western Turkmenia. Proc. Acad. Sci. USSR Ser. Phys. Earth, 3:73-82.

Hillhouse, J., and Cox, A., 1976. Brunhes-Matuyama polarity transition. Earth Planet. Sci. Lett., 29:51-64.

Ninkovich, D., Opdyke, N. D., Heezen, B. C., and Foster, J. H., 1966. Paleomagnetic stratigraphy, rates of deposition and tephrachronology in North Pacific deep-sea sediments. Earth Planet. Sci. Lett., 1:476-492.

Opdyke, N. D., Kent, D. V., and Lowrie, W., 1973. Details of magnetic polarity transitions recorded in a high-deposition rate deepsea core. Earth Planet. Sci. Lett., 20:315-324.

Steinhauser, P., and Vincenz, S. A., 1973. Equatorial paleopoles and behavior of the dipole field during polarity transition. Earth Planet. Sci. Lett., 19:113-119.

Vadkovsky, V. N., Gurary, G. Z., and Mamikonyan, M. R., 1980. Analysis of the process of geomagnetic pole's sign change. Proc. Acad. Sci. USSR Ser. Phys. Earth, 7:55-69.

Date of Initial Receipt: August 20, 1982 